\title{
A survey of Australian dairy farmers to investigate animal welfare risks associated with increasing scale of production
}

\author{
D. S. Beggs, ${ }^{1}$ A. D. Fisher, E. C. Jongman, and P. H. Hemsworth \\ Animal Welfare Science Centre, Faculty of Veterinary and Agricultural Sciences, University of Melbourne, Werribee, 3030, Australia
}

\begin{abstract}
Although large herds (more than 500 cows) only represent $13 \%$ of Australian dairy farms, they represent more than $35 \%$ of the cows milked. A survey of Australian dairy farmers was conducted to assess relationships between herd size and known or proposed risk factors for adverse animal welfare outcomes in Australian dairy herds in relation to increasing scale of production. Responses from 863 Australian dairy farms (13\% of Australian dairy farms) were received. Increasing herd size was associated with increases in stocking density, stock per labor unit, and grain fed per day - all of which could reasonably be hypothesized to increase the risk of adverse welfare outcomes unless carefully managed. However, increasing herd size was also associated with an increased likelihood of staff with formal and industry-based training qualifications. Herd size was not associated with reported increases in mastitis or lameness treatments. Some disease conditions, such as milk fever, gut problems, and down cows, were reported less in larger herds. Larger herds were more likely to have routine veterinary herd health visits, separate milking of the main herd and the sick herd, transition diets before calving, and written protocols for disease treatment. They were more likely to use monitoring systems such as electronic identification in the dairy, computerized records, daily milk yield or cell count monitoring, and pedometers or activity meters. Euthanasia methods were consistent between herds of varying sizes, and it was noted that less than $3 \%$ of farms make use of captive-bolt devices despite their effectiveness and ready availability. Increasing herd size was related to increased herd milking time, increased time away from the paddock, and increased distance walked. If the milking order of cows is consistent, this may result in reduced feed access for late-milking-order cows because of a difference in time away from the paddock. More than $95 \%$ of farmers believed that their cows were content most of the time, and cows were
\end{abstract}

Received December 14, 2014.

Accepted April 7, 2015.

${ }^{1}$ Corresponding author: dbeggs@unimelb.edu.au reported as well behaved on more than $90 \%$ of farms. Although the potential animal welfare issues appear to be different between herd sizes, no evidence existed for a relationship between herd size and adverse welfare outcomes in terms of reported disease or cow contentment levels.

Key words: animal welfare, herd size, animal health, dairy farm

\section{INTRODUCTION}

Animal health and animal welfare are contributors to dairy production efficiency, as well as being important to the general public and dairy consumers. Increasing scale of production is a confirmed trend in most developed dairy industries (Lean et al., 2008; Verkerk and Hemsworth, 2010), including the Australian dairy industry, where dairy farms are predominantly outdoor, pasture-based systems. According to a national dairyfarmer survey conducted by Dairy Australia in early 2013, the average Australian herd size has increased $37 \%$ over the past 10 yr. Since 2004, the proportion of farms with herds milking in excess of 300 cows significantly increased from $17 \%$ in 2004 to $30 \%$ in 2013 , and at the other end of the scale, small farms $(<150$ cows) now account for $26 \%$ of all farms compared with $35 \%$ in 2004 . The trend toward larger farms looks set to continue, with $33 \%$ of farmers surveyed expecting to calve more cows in the following year (Dairy Australia, 2013a).

Increasing scale of production in extensive dairy systems can be associated with larger herd sizes, increased stocking densities, longer milking times, longer walking distances, and reduced ability to examine and treat cows individually. Factors such as these have the capacity to cause reduced welfare outcomes for dairy cows if not properly managed (Verkerk and Hemsworth, 2010). On the other hand, there are management aspects that may improve outcomes with economies of scale. It seems probable, although little objective data are available to support it, that larger enterprises are more likely to have more modern dairies that reduce milking time; they may be more likely to have infrastructure to electronically identify and monitor individual cows; 
they may be more likely to use professional advice and provide superior nutrition; and they may have greater capacity to provide staff training and general quality assurance systems.

Little has been published regarding animal welfare outcomes for cows in large Australian dairy herds. A review of livestock disease threats associated with intensification of pastoral dairy farming (Lean et al., 2008) reported that although evidence exists that increased production increases the risk of mastitis and culling for udder health, the evidence to support an increased risk of most diseases was sparse, and indeed, diseases such as bloat and ketosis seem to have lower risk. The same report concludes that mineral nutrition of pasture-fed cattle is being better addressed, with gains in the control of milk fever, hypomagnesaemia, and trace-element deficiencies, but that lameness, anthelmintic resistance, and ruminal acidosis may be at increased risk with increasing scale of production.

Studies documenting affective state and naturalness are also sparse with regard to larger extensively managed dairy herds. It has been established that the amount of time a cow spends lying down and resting can substantially affect its comfort and welfare (Overton et al., 2002; Fisher et al., 2003). It seems logical that as herds increase in size, cows may experience reduced lying and resting times as milking time and the time taken to walk to and from the dairy increaseparticularly in farms where loafing or feed pads are used (Botheras, 2006).

An agreed definition of "animal welfare" has been adopted by the World Organization for Animal Health and many other organizations worldwide (Fraser et al., 2013; OIE World Organization for Animal Health, 2014):

"Animal welfare means how an animal is coping with the conditions in which it lives. An animal is in a good state of welfare if (as indicated by scientific evidence) it is healthy, comfortable, well nourished, safe, able to express innate behaviour, and if it is not suffering from unpleasant states such as pain, fear, and distress. Good animal welfare requires disease prevention and veterinary treatment, appropriate shelter, management, nutrition, humane handling and humane slaughter/ killing. Animal welfare refers to the state of the animal; the treatment that an animal receives is covered by other terms such as animal care, animal husbandry, and humane treatment."

To assess relationships between herd size and known or proposed risk factors for adverse animal welfare outcomes in Australian dairy herds, we designed a farmer survey with variables that included (1) animal indices of poor welfare (e.g., disease and lameness) and (2) strategies or policies that are known or hypothesized to affect animal welfare (e.g., veterinary and nutritional practices, training, and technology to monitor cow behavior). It was proposed that a better understanding of these relationships will inform further efforts to mitigate and measure adverse welfare outcomes with increasing scale of production.

\section{MATERIALS AND METHODS}

\section{Farm Sample}

We aimed to survey Australian dairy farms via a combination of electronic and physical distribution. A physical survey with a link to an electronic version was included in the September 2014 edition of The Australian Dairyfarmer magazine - an industry publication that is distributed free of charge to all registered Australian dairy farmers. A link to an electronic survey was also sent by e-mail to a random sample of 1,000 farmers who had opted in to receiving communications from Dairy Australia Limited (the national Dairy Research and Development Corporation).

The survey was anonymous, and in the instructions we requested that only one survey per farm be submitted. This study was conducted with human research ethics approval from The University of Melbourne (Ethics identity 1141608 1).

\section{Questionnaire}

Data were collected from September to November 2014 by means of physical and electronic questionnaires that were returned in a reply paid envelope or submitted online via an electronic survey company. The questionnaire was anonymous and consisted of 28 closed-ended questions, some of which contained multiple parts. The first questions gathered information about farm location, herd size, physical area, level of milk production, grain feeding, dairy type, staffing levels, and qualifications.

Other questions were designed to collect information about risk factors for animal welfare outcomes that are (1) indicative of poor welfare (animal-based indices) or (2) strategies or policies that are known or hypothesized to affect animal welfare across the 3 overlapping quality-of-life domains of biological function, affective state, and naturalness. The survey included questions about reproduction, mastitis, and other diseases. Quantitative factors such as disease levels were recorded but also information about how such levels are monitored on farm. For example, having electronic identification and computerized records may allow for better monitoring 
Table 1. Survey respondents as a percentage of the total number of dairy farms in each Australian dairying region

\begin{tabular}{lcrl}
\hline Dairying region & Respondents & $\begin{array}{c}\text { No. of } \\
\text { farms }\end{array}$ & $\%$ \\
\hline Dairy NSW & 102 & 437 & 23 \\
Dairy SA & 48 & 279 & 17 \\
Dairy Tas & 66 & 413 & 16 \\
Gipps Dairy & 194 & 1,548 & 13 \\
Murray Dairy & 177 & 1,663 & 11 \\
Subtropical Dairy & 72 & 700 & 10 \\
Western Dairy & 34 & 162 & 21 \\
Westvic Dairy & 169 & 1,438 & 12 \\
Total & 863 & 6,640 & 13 \\
\hline
\end{tabular}

of disease. In relation to how quickly cows with welfare needs are identified and treated, there were questions on euthanasia methods; the use of noxious stimuli such as electric wire on backing gates; the use of electric prodders and poly pipe (polyethylene pipe) goading implements; and farmer views about the contentment level, behavior, and fear levels of cows. There were also questions on time spent on and off pasture such as the time out of a paddock, the time spent walking, and the likelihood of individual cows spending more than $2 \mathrm{~h}$ standing in a yard waiting to be milked.

\section{Statistical Analyses}

Data were entered into a database and checked for typographical errors and duplicates. Herds were stratified into 5 categories based on the maximum number of cows that were milked together as a group for more than 3 mo. Farms were stratified into categories consistent with the Australian National Dairy Farm Survey (Dairy Australia, 2014): <150 (very small); 150 to 300 (small); 301 to 500 (medium); 501 to 750 (large); and $751+$ (very large).

Statistical analyses were performed using SPSS (Version 22, IBM Corp., Armonk, NY). Means were compared between different herd-size groups using one-way ANOVA. Confidence intervals of the mean differences between different herd-size groups were made using Gabriel's pairwise method, as sample sizes were not similar between groups (Field, 2013). Differences in proportions between herd-size groups were tested using the SPSS Crosstabs function to perform a chi-squared analysis with correction for multiple comparisons using a Bonferroni technique.

\section{RESULTS AND DISCUSSION}

\section{Responses and Data Validation}

After discarding blank surveys $(\mathrm{n}=56)$ and those that were completed by respondents who did not have an active role in an Australian dairy farm $(\mathrm{n}=4)$, a total of 863 valid surveys were returned. Australia's dairy farms are commonly divided into 8 distinct geographical dairying regions, each serviced by a different regional development program (Dairy Australia, 2014). The response rate as a percentage of the total number of dairy farms in each region (K. Davis, Dairy Australia, Melbourne, Australia, personal communication) are described in Table 1 . These response rates varied between 10 and $23 \%$ for individual regions and accounted for $13 \%$ of Australian dairy farms. The total number of milking cows accounted for in the survey was approximately 260,000 , which was $15.6 \%$ of the 1.65 million cows (Dairy Australia, 2013b) that were milked in Australia.

A limitation of the survey design is that we could not be certain that The Australian Dairyfarmer magazine that contained the survey was read on all farms, which makes it likely that our response rates are underestimates of the response rates on farms on which the survey was read. It is also possible that duplicate surveys were returned for some farms despite the survey instructions. A check for duplicates based on similar dairying region, dairy type, number of cows, farm size in hectares, and number of paddocks did not produce any likely duplicate entries.

The mean herd size was $304(\mathrm{SD}=252$, median $=$ 230). The distribution of farm sizes and number of cows accounted for are described in Table 2. Although large herds (more than 500 cows) only represent $13 \%$ of Australian dairy farms, they represent more than $35 \%$ of the cows milked.

Our responses appear comparable with a 2012 phone survey of 1,000 Australian dairy farmers, where the av-

Table 2. The number and percentage of farms and cows in herds of different sizes represented in the survey results

\begin{tabular}{lrrrrrr}
\hline & \multicolumn{5}{c}{ Herd size } & \\
\cline { 2 - 5 } Item & $<150$ & $150-300$ & $301-500$ & $501-700$ & $701+$ & Total \\
\hline Farms (no.) & 172 & 395 & 166 & 66 & 49 & 848 \\
\% of farms & 20 & 47 & 20 & 8 & 5 & 100 \\
\% of cows & 7 & 33 & 26 & 16 & 19 & 100 \\
\hline
\end{tabular}


erage number of cows milked was 299, 30\% of all farms milked more than 300 cows, and $26 \%$ of farms milked less than 150 cows (Dairy Australia, 2013a).

\section{Farm Management and Economies of Scale}

Table 3 shows that increasing herd size was associated with known or hypothesized risk factors for adverse welfare outcomes such as increasing stocking densities, number of stock per person, and the level of grain or concentrate feeding per cow during milking as farmers attempt to achieve economies of scale.

As stocking densities increase, risk of infectious disease spread through increased frequency of contact between individuals theoretically increases, although quantitative data to support such an assertion are sparse - indeed a review on the subject reported that smaller herds were more likely to have cows culled for mastitis, although larger herds were more likely to cull cows for lameness (Lean et al., 2008). Reduced paddock area per cow might affect welfare through competitive and agonistic behavioral challenges associated with closer contact.

As the number of stock per labor unit increases, there is a risk that welfare outcomes might be affected by a reduced ability to monitor for issues and to deal with them appropriately and in a timely manner once identified.

On Australian dairy farms, TMR feeding is uncommon. Most cows are fed most of their diet from pasture and other forages in the paddock or on feed pads, with grain mixes (concentrates) pulse fed in the dairy during milking. Increasing the amount of grain or concentrates that are pulse fed to cattle during milking increases the risk of diseases secondary to overfeeding grain. These factors might translate into welfare risks for cows in terms of lameness and other transition-cow diseases (von Keyserlingk et al., 2009; Lean et al., 2010). At the other end of the spectrum, if smaller farms were underfeeding their cows, this would be difficult to assess with our data set but would likely be expressed through an increase in secondary adverse outcomes such as disease treatment levels.

Although in theory the 3 mechanisms described above could lead to increased adverse welfare outcomes, no evidence for this was found in this study. It may be possible to mitigate these risks through infrastructure or management changes, and it is possible that these changes are easier or more practical to implement on larger farms.

For example, the risk of disease spread can be addressed through biosecurity measures and having superior disease-identification and treatment protocols. The risk of reduced observation of problems as the

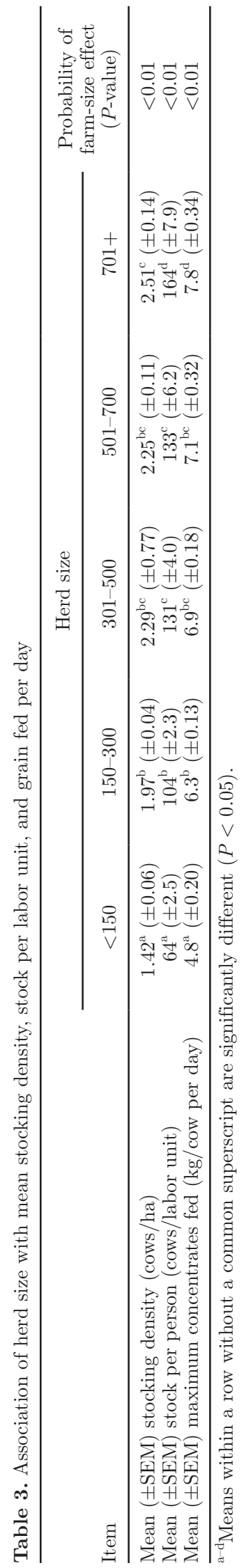

Journal of Dairy Science Vol. 98 No. 8, 2015 
Table 4. The association between herd size and the percentage of farms with employees that had completed industry training or formal qualifications

\begin{tabular}{lrrrrr}
\hline & \multicolumn{5}{c}{ Herd size } \\
\cline { 2 - 6 } Item & $<150$ & $150-300$ & $301-500$ & $501-700$ & $701+$ \\
\hline Industry training (\%) & $39^{\mathrm{a}}$ & $57^{\mathrm{b}}$ & $69^{\mathrm{bc}}$ & $90^{\mathrm{d}}$ & $84^{\mathrm{cd}}$ \\
Formal qualification (\%) & $21^{\mathrm{a}}$ & $39^{\mathrm{b}}$ & $55^{\mathrm{c}}$ & $71^{\mathrm{c}}$ & $63^{\mathrm{c}}$ \\
Any training or qualification (\%) & $44^{\mathrm{a}}$ & $67^{\mathrm{b}}$ & $78^{\mathrm{b}}$ & $97^{\mathrm{c}}$ & $86^{\mathrm{bc}}$ \\
\hline
\end{tabular}

${ }^{\mathrm{a}-\mathrm{d}}$ Means within a row without a common superscript are significantly different $(P<0.05)$.

number of stock per labor unit increases could be addressed by better education and superior automated electronic monitoring, and the risk of acidosis as higher grain levels are fed could be addressed through superior transition-cow management.

\section{Education, Skills, and Herd Size}

It seems logical that animal welfare outcomes might be improved when farms have staff that are better qualified. We asked whether any farm employees had completed a range of relevant industry training courses. For the purposes of analysis, we divided training into informal industry courses and formal tertiary education courses that are related to dairying or agriculture. Table 4 shows that larger herds were more likely to have employees with formal qualifications or industry training. There may be an opportunity to improve animal welfare outcomes by targeting short industry training courses at farms with small to medium herd sizes.

\section{Associations Between Reported Disease Treatment and Herd Size}

Table 5 shows no association existed between increasing herd size and reported levels of treatment for mastitis or lameness. Larger herds were more likely to report less milk fever and gastrointestinal problems, as well as less down cows. A limitation of these data is that there was no standardized way of recording or defining these problems, and it is possible that farms differed in the way that the conditions were recorded and the severity of disease where treatment was instituted.

Previous reports show that farmers tend to underestimate the incidence of disease, especially when compared with observations from an outside observer (Bartlett et al., 2001; Espejo et al., 2006; Mörk et al., 2009). In one study, the incidence of clinical lameness was underestimated by a factor of 3 (Wells et al., 1993).

We asked farmers to report the number of cows treated for disease conditions in the previous 12-mo period (rather than estimate clinical disease levels). It was thought that treatment records, which are required as part of the milk factory quality assurance schemes, should be readily available on most farms, and a clear instruction was included to leave the question blank if the respondent was unsure. It should be noted that the level of treated disease will always underestimate the true underlying level of disease.

\section{Risk Factors for Disease Spread and Treatment}

As stocking density increases, it could be expected that disease spread would be more likely. The ReedFrost epidemic model that is used to explain population disease spread contains a factor that explicitly accounts for the frequency of contact between animals (Lean et al., 2008). Having a biosecurity plan to prevent disease introduction, milking sick cows separately from others, having routine veterinary herd health visits, and having written protocols for disease treatment might affect the treatment or spread of disease. Table 6 shows that larger herds were more likely to milk the sick cows as a separate herd, and very small herds were less likely to undertake routine veterinary herd health visits.

The absence of a biosecurity plan is a risk factor for animal welfare if it is reasonable to assume that following a formal plan would represent a decreased disease risk. We noted that less than $20 \%$ of farms had a biosecurity plan, and this was not related to farm size. We believe that this is an area where significant improvement might be made in the Australian dairy industry.

The use of a well-planned transition diet in the weeks before calving can have a positive effect on animal welfare through a reduction in diseases such as hypocalcaemia, downer cows, ketosis, udder edema, abomasal displacement, retained fetal membranes, lameness, and grain overload (Lean et al., 2010). Although we could not assess the quality or effectiveness of the transition diet, we noted that as herd size increased, the proportion of herds that used a special transition diet before calving increased but only to a level of approximately $75 \%$. It would seem that there may be scope to improve animal welfare outcomes by increasing the adoption of specific transition diets in farms of all sizes. 


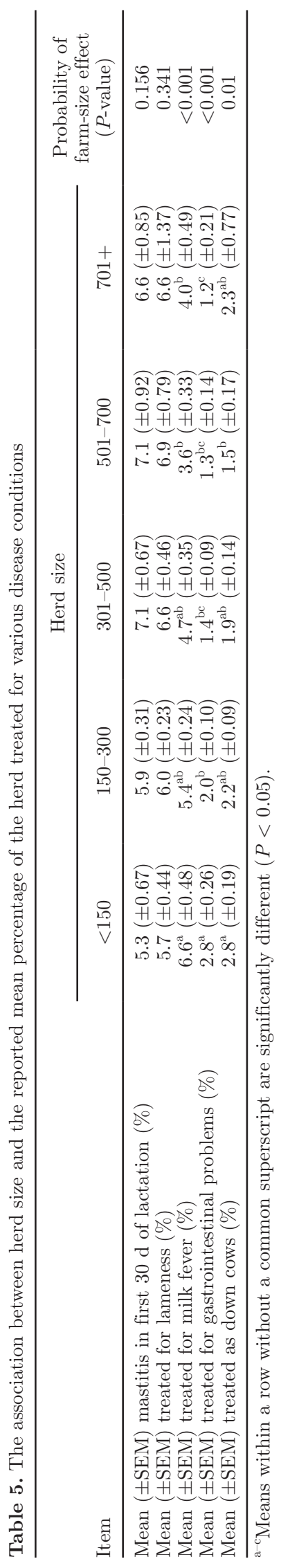

\section{Activities to Monitor Health and Disease}

As the number of cows per labor unit increases, many strategies can be employed to automate monitoring for problems. Table 7 shows the proportion of herds in each size category that used various monitoring strategies. The percentage of farms with electronic identification in the dairy was related to herd size. Measuring daily cell counts or milk conductivity and having computerized herd records was more likely in herds with more than 300 cows. Despite the extra monitoring in larger herds, more than $90 \%$ of respondents in all herd sizes agreed that sick cows were identified and treated quickly on their farms.

\section{Risk Factors for Fear and Distress}

Freedom from fear and distress, by ensuring conditions and treatment that prevent mental suffering, is one of the "Five Freedoms" (Brambell, 1965; McCulloch, 2012) and is an important component of both the biological functioning state and affective state domains of animal welfare.

The capacity of farmers to provide effective euthanasia in a timely manner to cattle that are suffering is an important factor in minimizing the distress of cattle that are suffering conditions that are untreatable for medical or economic reasons. Current legal methods recommended for euthanasia of cattle in Australia include gunshot, captive bolt, and lethal injection administered under veterinary supervision. Blunt trauma to the head of calves less than $24 \mathrm{~h}$ of age and exsanguination are permitted if no other methods are available (Animal Health Australia, 2012). The licensing and use of firearms has been strictly controlled in Australia for some time. Euthanasia on farm may be carried out by farmers using firearms (which have special license, storage, and occupational health and safety requirements) or captive-bolt guns (which although they require care in their use, do not have licensing requirements in most states in Australia). Farmers who do not have firearms or captive-bolt devices on farm commonly use their veterinarian or a local knackery service for euthanasia. Knackeries are businesses that provide a service for disposal of farm animals that are not fit for human consumption by either processing the carcass for pet food or rendering it into meat and bone meal for incineration and use as fertilizer.

Knackeries have the advantage that they remove and dispose of the carcass, but the possibility of delayed attendance and thus delayed euthanasia is a risk to animal welfare. Table 8 shows the euthanasia methods reported in this survey. Although large and small farms did not significantly differ, it is of concern that $23 \%$ of 
Table 6. The association between herd size and the percentage of farms undertaking activities likely to assist with treatment or prevention of disease spread

\begin{tabular}{lccccc}
\hline & \multicolumn{5}{c}{ Herd size } \\
\cline { 2 - 6 } Item & $<150$ & $150-300$ & $301-500$ & $501-700$ & $701+$ \\
\hline Routine herd health visits (\%) & $17^{\mathrm{a}}$ & $33^{\mathrm{b}}$ & $39^{\mathrm{b}}$ & $46^{\mathrm{b}}$ & $41^{\mathrm{b}}$ \\
Sick herd milked separately (\%) & $19^{\mathrm{a}}$ & $27^{\mathrm{a}}$ & $51^{\mathrm{b}}$ & $69^{\mathrm{bc}}$ & $82^{\mathrm{c}}$ \\
Have biosecurity plan (\%) & 10 & 13 & 17 & 14 & 16 \\
Written protocols for mastitis (\%) & 67 & 71 & 75 & 74 & 86 \\
Written protocols for disease (\%) & 47 & 44 & 45 & 52 & 45 \\
Special transition diet before calving (\%) & $41^{\mathrm{a}}$ & $65^{\mathrm{b}}$ & $77^{\mathrm{bc}}$ & $76^{\mathrm{bc}}$ & $86^{\mathrm{c}}$ \\
Main herd milked in separate groups (\%) & $2^{\mathrm{b}}$ & $6^{\mathrm{b}}$ & $15^{\mathrm{a}}$ & $26^{\mathrm{c}}$ & $45^{\mathrm{c}}$ \\
\hline
\end{tabular}

${ }^{\mathrm{a}-\mathrm{c}}$ Means within a row without a common superscript are significantly different $(P<0.05)$.

farms overall relied solely on the knackery to provide euthanasia services. Ownership of penetrating captivebolt guns for euthanasia of livestock is being promoted to Australian farmers because they are considered safer, they have fewer restrictions than firearms, and cheaper models are now readily available (Jubb, 2013). Despite recent publicity and training programs in Australia, the uptake of captive-bolt use is still low (3\% of all farms), and this provides an opportunity for welfare improvement. Increased use of captive-bolt devices would reduce the need for using blunt trauma for euthanasia of calves less than $24 \mathrm{~h}$ old - a practice that is aesthetically unpleasant and where there is significant risk of poor welfare outcomes because of issues with operator training and error.

Assessing distress (or contentment) of dairy cattle using a survey is difficult, but it is possible to measure some known causes of distress (for example, the use of backing gates or goads to move cattle). It is possible to measure farmer attitudes and opinions regarding indirect and qualitative measures of well-being such as friendliness and contentment. Table 9 shows some risk factors for both positive and negative affective state outcomes.

The use of the backing gate to push cows and the presence of electric wire on the backing gate was lower in very small herds. The use of polyethylene pipe goads was lower in larger herds, and the use of electric prod- ders was similar, with $85 \%$ or farms overall never using electric goads.

In more than $90 \%$ of responses, farmers reported that they lost their tempers with cows less than weekly or never, that some cows were friendly toward people, that their cows were well behaved, and that their cows were not generally fearful when someone walked through the dairy yard. Herd size did not affect these variables. More than $95 \%$ of respondents believed their cows were content most of the time. Fearfulness has been proposed as a means to assess the value of human-animal interactions, and although difficult to standardize and interpret, the general principle that good welfare is consistent with friendliness and good behavior is sound (Verkerk and Hemsworth, 2010).

Herds with more than 300 cows were more likely to have cows standing in the yard for more than $2 \mathrm{~h}$ before being milked (Table 9). Although this is not necessarily a problem in isolation, increasing time off pasture can reduce the potential for cows to exhibit natural behavior and may be associated with hunger, thirst, or feet problems associated with standing on concrete for long periods. Previous studies have shown that restricting the ability of cows to spend time lying down was associated with negative welfare outcomes (Fisher et al., 2003).

We hypothesized that in larger herds it might be expected that cows need to walk further to the dairy

Table 7. The association between herd size and the percentage of farms undertaking activities likely to assist with herd monitoring

\begin{tabular}{|c|c|c|c|c|c|}
\hline Item & \multicolumn{5}{|c|}{ Herd size } \\
\hline Electronic ID in dairy (\%) & $5^{\mathrm{a}}$ & $17^{\mathrm{b}}$ & $41^{\mathrm{c}}$ & $64^{\mathrm{d}}$ & $92^{\mathrm{e}}$ \\
\hline Computerized herd records $(\%)$ & $22^{\mathrm{a}}$ & $53^{\mathrm{b}}$ & $72^{\mathrm{c}}$ & $82^{\mathrm{c}}$ & $90^{\mathrm{c}}$ \\
\hline Agree sick cows identified and treated quickly (\%) & 92 & 96 & 92 & 94 & 94 \\
\hline Pedometers or activity meters $(\%)$ & $1^{\mathrm{a}}$ & $4^{\mathrm{ab}}$ & $4^{\mathrm{ab}}$ & $11^{\mathrm{b}}$ & $8^{b}$ \\
\hline
\end{tabular}

${ }^{\mathrm{a} e}$ Means within a row without a common superscript are significantly different $(P<0.05)$. 
Table 8. The percentage of farms that undertake various methods of euthanasia

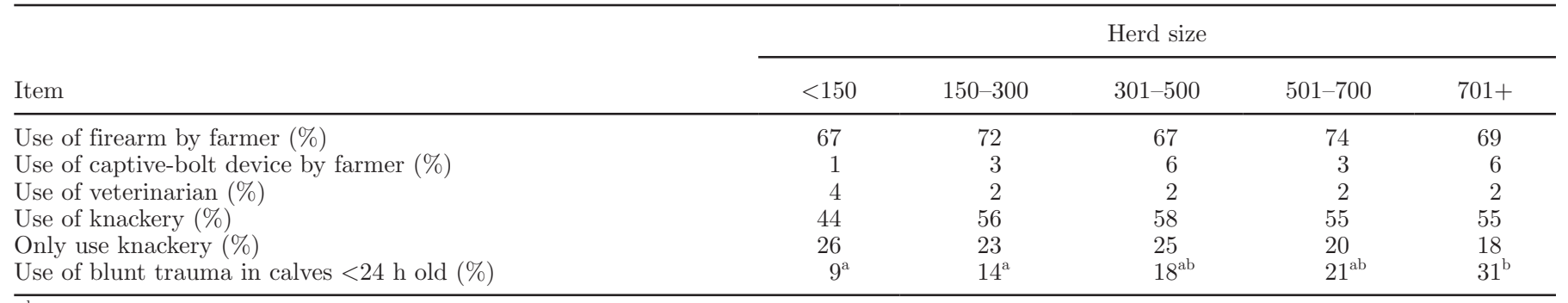

${ }^{\mathrm{a}, \mathrm{b}}$ Means within a row without a common superscript are significantly different $(P<0.05)$.

and milking the herd would take longer, which would mean that cows were out of their paddock for longer periods. Indeed, the survey found that farmers reported that milking the herd took longer, cows were out of the paddock for longer, and they walked further as herd size increased (Table 10). Minimum time out of a paddock did not differ. This may have implications for animal welfare outcomes, particularly if cows enter the dairy in a consistent order because the later cows might have consistently longer time off pasture and standing on concrete. This could be mitigated to some extent by milking the herd in more than one separate group, and as shown in Table 6, as herd size increases, more farmers milked the main herd in separate groups. Some farms may lock all the cows in the yard before milking commences, and others may start milking as cows are being brought up from the paddock. The farmer reports on time of a typical milking, the longest time a cow would be out of the paddock, and the longest distance walked, are shown in Table 10. In our survey, 99\% of respondents agreed or strongly agreed that cows usually enter the dairy in a similar order each day except when they are sick or on heat. There is little evidence in the literature on effects of the milking order of cows in larger herds, and work in this area is warranted.

\section{CONCLUSIONS}

Although large herds (>500 cows) only represent 13\% of Australian dairy farms, they are important in terms of animal welfare because they represent more than $35 \%$ of the cows milked. Increasing herd size was associated with known or proposed risk factors for adverse animal welfare outcomes including increased stocking density, decreased labor units per cow, increased grain feeding, increased milking time, increased time away from the paddock, and increased distance walked. Increasing herd size was also associated with factors that could be proposed to reduce the risk of adverse welfare outcomes such as greater capacity for strategies such as better training and education of staff, routine veterinary herd health visits, separate milking of the main herd and the sick cows, transition diets before calving, and written protocols for treatment of disease. Although the potential animal welfare issues appear to be different between herd sizes, there was no evidence for a relationship between herd size and adverse welfare outcomes in terms of reported disease or cow contentment levels. Further work is indicated to examine the effects of increased time away from the paddock on cow welfare. Further emphasis on the development of farm

Table 9. The association between herd size and risk factors that may be associated with fear or distress when cows are being handled or milked

\begin{tabular}{|c|c|c|c|c|c|}
\hline Item & \multicolumn{5}{|c|}{ Herd size } \\
\hline Electric wire on backing gate $^{1}(\%)$ & $3^{\mathrm{b}}$ & $17^{\mathrm{a}}$ & $19^{\mathrm{a}}$ & $26^{\mathrm{a}}$ & $27^{\mathrm{a}}$ \\
\hline Cows are fearful when a person walks through the milking yard ${ }^{1}(\%)$ & 4 & 6 & 6 & 5 & 2 \\
\hline Cows often stand for more than $2 \mathrm{~h}$ before being milked $^{1}(\%)$ & $5^{\mathrm{b}}$ & $10^{\mathrm{b}}$ & $20^{\mathrm{a}}$ & $33^{\mathrm{a}}$ & $27^{\mathrm{a}}$ \\
\hline Never use poly pipe goad on a cow (\%) & $37^{\mathrm{ab}}$ & $33^{\mathrm{a}}$ & $49^{\mathrm{bc}}$ & $56^{\mathrm{bc}}$ & $67^{\mathrm{c}}$ \\
\hline Some cows are friendly toward people $(\%)$ & 94 & 93 & 91 & 95 & 92 \\
\hline Cows are content most of the time $(\%)$ & 99 & 98 & 99 & 95 & 100 \\
\hline Cows are well behaved in the dairy and yard (\%) & 93 & 94 & 90 & 94 & 90 \\
\hline
\end{tabular}

${ }^{\mathrm{a}-\mathrm{c}}$ Means within a row without a common superscript are significantly different $(P<0.05)$.

${ }^{1}$ Factor associated with negative outcomes (a lower percentage is better). 
Table 10. The association between herd size and time for milking, out of paddock and distance walked for farms of different sizes

\begin{tabular}{|c|c|c|c|c|c|}
\hline Item & \multicolumn{5}{|c|}{ Herd size } \\
\hline Mean time for typical milking (min) & $83^{\mathrm{a}}$ & $108^{\mathrm{b}}$ & $126^{\mathrm{c}}$ & $158^{\mathrm{c}}$ & $186^{\mathrm{d}}$ \\
\hline Mean longest time out of paddock (min) & $137^{\mathrm{a}}$ & $179^{\mathrm{b}}$ & $207^{\mathrm{bc}}$ & $231^{\mathrm{c}}$ & $236^{\mathrm{c}}$ \\
\hline Walking distance to furthest paddock (km) & $1.1^{\mathrm{a}}$ & $1.6^{\mathrm{b}}$ & $1.9^{\mathrm{bc}}$ & $2.0^{\mathrm{bc}}$ & $2.3^{\mathrm{c}}$ \\
\hline
\end{tabular}

${ }^{\mathrm{a}-\mathrm{d}}$ Means within a row without a common superscript are significantly different $(P<0.05)$.

biosecurity plans and the use of captive-bolt devices for euthanasia is warranted in herds of all sizes.

\section{ACKNOWLEDGMENTS}

The authors thank the Victorian Department of Environment (Melbourne, Australia) and Primary Industries and Dairy Australia Ltd. (Melbourne, Australia) for their support of this project.

\section{REFERENCES}

Animal Health Australia. 2012. Australian animal welfare standards and guidelines-Land transport of livestock. 1.1 ed. Animal Health Australia, Canberra, Australia. http://animalwelfarestandards. net.au.

Bartlett, P. C., J. F. Agger, H. Houe, and L. G. Lawson. 2001. Incidence of clinical mastitis in Danish dairy cattle and screening for non-reporting in a passively collected national surveillance system. Prev. Vet. Med. 48:73-83. http://dx.doi.org/10.1016/S01675877(00)00192-6.

Botheras, N. A. 2006. The behavior and welfare of grazing dairy cows (Bos taurus): Effects of time away from pasture. PhD Thesis. University of Melbourne, Australia.

Brambell, F. W. R. 1965. Report of the technical committee to inquire into the welfare of animals kept under intensive livestock husbandry systems. HMSO Cmnd. 2836, London, UK.

Dairy Australia. 2013a. Dairy Australia - Situation and Outlook 2013. Melbourne, Australia. Accessed Mar. 9, 2015. http://www. dairyaustralia.com.au/Markets-and-statistics/Market-situationand-outlook.aspx.

Dairy Australia. 2013b. Australian Dairy Industry In Focus 2013. Melbourne, Australia. Accessed Mar. 9, 2015. http://www. dairyaustralia.com.au/Markets-and-statistics/Market-situationand-outlook.aspx.

Dairy Australia. 2014. Dairy Situation and Outlook-May 2014 Update. Accessed Mar. 9, 2015. http://www.dairyaustralia.com.au/ Markets-and-statistics/Market-situation-and-outlook.aspx.

Espejo, L. A., M. I. Endres, and J. A. Salfer. 2006. Prevalence of lameness in high-producing Holstein cows housed in freestall barns in Minnesota. J. Dairy Sci. 89:3052-3058.

Field, A. 2013. Discovering Statistics Using IBM SPSS Statistics. 4th ed. Sage Publ. Ltd., London, UK.
Fisher, A. D., M. Stewart, G. A. Verkerk, C. J. Morrow, and L. R Matthews. 2003. The effects of surface type on lying behaviour and stress responses of dairy cows during periodic weather-induced removal from pasture. Appl. Anim. Behav. Sci. 81:1-11. http:// dx.doi.org/10.1016/S0168-1591(02)00240-X.

Fraser, D., I. J. H. Duncan, S. A. Edwards, T. Grandin, N. G. Gregory, V. Guyonnet, P. H. Hemsworth, S. M. Huertas, J. M. Huzzey, D. J. Mellor, J. a. Mench, M. Špinka, and H. R. Whay. 2013. General Principles for the welfare of animals in production systems: The underlying science and its application. Vet. J. 198:19-27. http:// dx.doi.org/10.1016/j.tvjl.2013.06.028.

Jubb, T. 2013. How to use a penetrating captive bolt gun. F3.3.1-10 in Proc. AVA Annu. Conf. Australian Vet. Assoc., Cairns, Australia.

Lean, I., P. Degaris, and S. Little. 2010. Transition Cow Management: Veterinarians and Farm Advisers. Dairy Australia, Melbourne, Australia.

Lean, I., C. Westwood, and M. Playford. 2008. Livestock disease threats associated with intensification of pastoral dairy farming. N. Z. Vet. J. 56:261-269. http://dx.doi.org/10.1080/00480169.2 008.36845

McCulloch, S. P. 2012. A critique of FAWC's five freedoms as a framework for the analysis of animal welfare. J. Agric. Environ. Ethics 26:959-975.

Mörk, M., A. Lindberg, S. Alenius, I. Vågsholm, and A. Egenvall. 2009. Comparison between dairy cow disease incidence in data registered by farmers and in data from a disease-recording system based on veterinary reporting. Prev. Vet. Med. 88:298-307. http://dx.doi.org/10.1016/j.prevetmed.2008.12.005.

OIE World Organization for Animal Health. 2014. Terrestrial Animal Health Code 2014. Accessed Dec. 15, 2014. http://web.oie.int/ eng/normes/mcode/en_glossaire.htm\#terme_animal.

Overton, M. W., W. M. Sischo, G. D. Temple, and D. A. Moore. 2002 Using time-lapse video photography to assess dairy cattle lying behavior in a free-stall barn. J. Dairy Sci. 85:2407-2413.

Verkerk, G. A., and P. H. Hemsworth. 2010. Managing cow welfare in large dairy herds. Pages 436-443 in Proceedings of the 4th Australasian Dairy Science Symposium 2010. Caxton Press, Hamilton, New Zealand.

von Keyserlingk, M. A. G., J. Rushen, A. M. de Passillé, and D. M. Weary. 2009. Invited review: The welfare of dairy cattle-key concepts and the role of science. J. Dairy Sci. 92:4101-4111. http:// dx.doi.org/10.3168/jds.2009-2326.

Wells, S. J., A. M. Trent, W. E. Marsh, and R. A. Robinson. 1993 Prevalence and severity of lameness in lactating dairy cows in a sample of Minnesota and Wisconsin herds. J. Am. Vet. Med. Assoc. $202: 78-82$ 